\title{
A chemo-enzymatic approach for the synthesis of human milk oligosaccharide backbone structures
}

\author{
Muschiol, Jan; Meyer, Anne S.
}

Published in:

Zeitschrift fuer Naturforschung. Section C: A Journal of Biosciences

Link to article, DOI:

10.1515/znc-2018-0149

Publication date:

2019

Document Version

Publisher's PDF, also known as Version of record

Link back to DTU Orbit

Citation (APA):

Muschiol, J., \& Meyer, A. S. (2019). A chemo-enzymatic approach for the synthesis of human milk oligosaccharide backbone structures. Zeitschrift fuer Naturforschung. Section C: A Journal of Biosciences, 74(34), 85-89. https://doi.org/10.1515/znc-2018-0149

\section{General rights}

Copyright and moral rights for the publications made accessible in the public portal are retained by the authors and/or other copyright owners and it is a condition of accessing publications that users recognise and abide by the legal requirements associated with these rights.

- Users may download and print one copy of any publication from the public portal for the purpose of private study or research.

- You may not further distribute the material or use it for any profit-making activity or commercial gain

- You may freely distribute the URL identifying the publication in the public portal

If you believe that this document breaches copyright please contact us providing details, and we will remove access to the work immediately and investigate your claim. 


\section{Rapid Communication}

Jan Muschiol* and Anne S. Meyer

\section{A chemo-enzymatic approach for the synthesis of human milk oligosaccharide backbone structures}

https://doi.org/10.1515/znc-2018-0149

Received September 30, 2018; revised November 15, 2018; accepted November 16, 2018

\begin{abstract}
The ability of an engineered $\beta$ - $N$-acetylhexosaminidase to utilize a reactive oxazoline as donor molecule for transglycosylation reaction to synthesize human milk oligosaccharide backbone structures was studied. The human milk oligosaccharide precursor lacto- $N$-triose II and three regioisomers could be synthesized using the oxazoline, which was either in situ-generated resulting in a chemo-enzymatic sequential cascade or was used as a purified compound. The highest observed concentration of overall transglycosylation products in a cascade reaction was $13.7 \mathrm{mM}$ after $18.5 \mathrm{~h}$, whereas the use of purified oxazoline resulted in $25.0 \mathrm{mM}$ of transglycosylation products after $6.5 \mathrm{~h}$. Remarkably, the in situ-generated oxazoline could be used without any further purification and it was shown that the used enzyme tolerated significant amounts of reagents such as triethylamine, which is reported for the first time for an enzyme from the glycoside hydrolase family 20.
\end{abstract}

Keywords: $\beta$ - $N$-acetylhexosaminidase; chemo-enzymatic cascade; human milk oligosaccharides; lacto- $N$-triose II; transglycosylation.

\section{Introduction}

Human milk oligosaccharides (HMOs) are well known for several beneficial effects on infants and their development. For example HMOs have anti-inflammatory and antiadhesive effects within the baby's gut and significantly contribute to the brain's development [1]. However, not every baby can get this precious mother's milk and therefore there is a strong need for high-quality infant

* Corresponding author: Jan Muschiol, Section for Protein Chemistry and Enzyme Technology, DTU Bioengineering, Technical University of Denmark, Søltofts Plads 221, 2800 Kongens Lyngby, Denmark, E-mail: jmus@dtu.dk.https://orcid.org/0000-0002-2852-6747 Anne S. Meyer: Section for Protein Chemistry and Enzyme Technology, DTU Bioengineering, Technical University of Denmark, Søltofts Plads 221, 2800 Kongens Lyngby, Denmark formulations containing HMOs [2]. In previous studies, we already demonstrated the enzymatic synthesis of the simplest HMO trisaccharides ( 2 '- and 3-fucosyllactose as well as $3^{\prime}$ - and 6'-sialyllactose) using differently engineered transglycosylases [3-7]. However, because human milk is very complex and also contains significant amounts of longer HMOs (e.g. lacto- $N$-tetraose (LNT)), we wanted to develop synthetic routes toward these molecules as well. For this purpose, two $\beta$ - $N$-acetylhexosaminidases (HEX1 and HEX2) were discovered in a metagenomic library, which were able to synthesize lacto- $N$-triose II (LNT2) from an unactivated donor molecule ( $N, N^{\prime}$-diacetylchitobiose ((GlcNAc) $\left.)_{2}\right)$ ) and lactose [8]. The two novel enzymes were classified as members of the glycoside hydrolase family 20 (GH20 family) according to the CAZy database (http://www.cazy.org/) [9]. Within this family, mainly exo-acting activities have been described (e.g. $\beta$ - $N$ acetylhexosaminidase) catalyzing the hydrolytic cleavage of hexosamines from oligosaccharides. All GH20 enzymes follow a common mechanism for catalysis, which involves neighboring group participation to form the reactive intermediate oxazoline $[10,11]$. Attempts to synthesize LNT using these enzymes with galactosidases in a cascade revealed that the wild-type transglycosylation activity of the $\beta-N$-acetylhexosaminidases was too low to be used in a cascade [12]. To address this issue, we recently described a mutant of HEX1, which had a ninefold higher transglycosylation activity [13]. Because the GH20 mechanism already involves an oxazoline as a reactive intermediate, we wanted to elaborate on the possibility of using the HEX $1_{\text {GTEPG }}$ mutant in combination with the well-known one-step aqueous synthesis of GlcNAc oxazoline [14, 15] to synthesize LNT2 enzymatically as depicted in Scheme 1.

\section{Materials and methods}

\subsection{Chemicals}

2-Chloro-1,3-dimethylimidazolinium chloride (DMC), 2-chloro-1,3-dimethyl-1 $H$-benzimidazol-3-ium chloride 


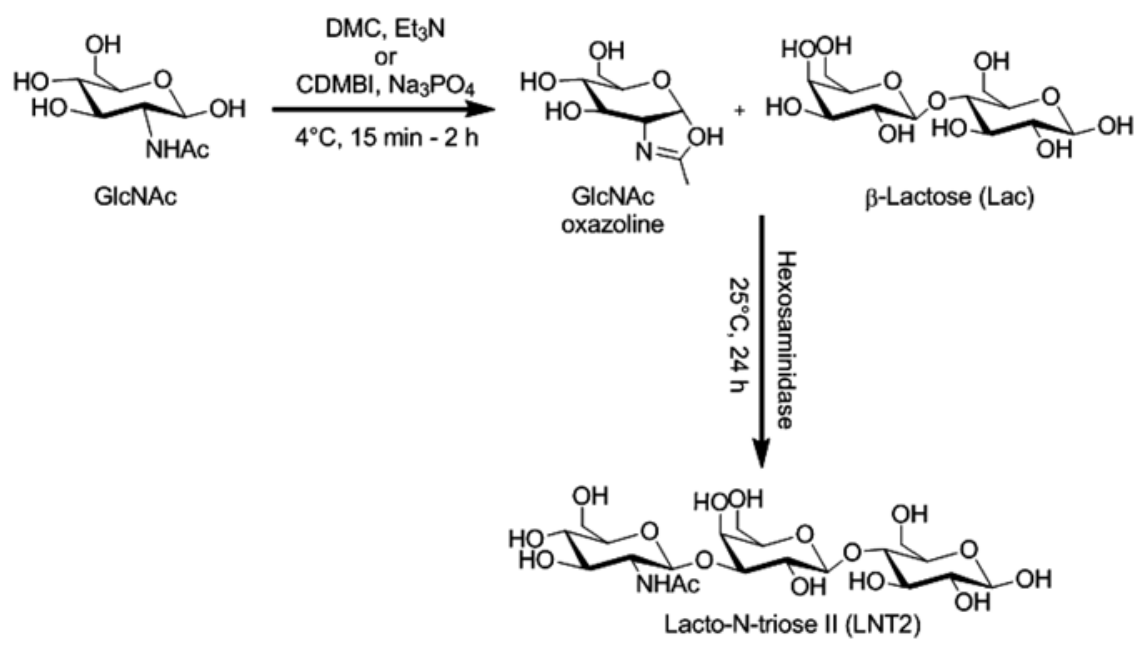

Scheme 1: Proposed chemo-enzymatic route toward the synthesis of lacto- $N$-triose II.

(CDMBI), 2-methyl-(1,2-dideoxy- $\alpha$-D-glucopyrano)-[2,1- $d$ ]-2oxazoline (GlcNAc oxazoline), and lacto- $N$-triose II (LNT2) were purchased from Carbosynth (Compton, UK). Trisodiumphosphate $\left(\mathrm{Na}_{3} \mathrm{PO}_{4}\right), \mathrm{N}$-acetylglucosamine, $\beta$-lactose, and kanamycin were purchased from Sigma-Aldrich (Steinheim, Germany). Triethylamine $\geq 99.5 \%\left(\mathrm{Et}_{3} \mathrm{~N}\right)$ was purchased from Carl Roth (Karlsruhe, Germany).

\subsection{Expression and purification of the enzyme}

Escherichia coli T7 express lysY harboring the pETM-10_ HEX1 $_{\text {GTEPG }}$ plasmid was used for expression. Therefore, a preculture was inoculated into autoinduction [16] medium containing kanamycin $(50 \mu \mathrm{g} / \mathrm{mL})$ and incubated for $2 \mathrm{~h}$ at $37^{\circ} \mathrm{C}$ and $180 \mathrm{rpm}$. Then, the temperature was set to $30^{\circ} \mathrm{C}$ and cultivation was continued overnight. The next day, cell harvest was carried out by centrifugation $(4400 \mathrm{~g}, 10 \mathrm{~min})$. The pellets were resuspended in binding buffer ( $20 \mathrm{mM}$ sodium phosphate, $500 \mathrm{mM} \mathrm{NaCl}$, $20 \mathrm{mM}$ imidazole, $\mathrm{pH}$ 7.8) and subsequently the cells were lysed by ultrasound (0.6 cycle, $100 \%$ amplitude on a UP400S, Hielscher Ultrasonics GmbH, Teltow, Germany). The cell debris was removed by centrifugation at $20,000 \mathrm{~g}$ for $20 \mathrm{~min}$ at $4{ }^{\circ} \mathrm{C}$. The enzyme was purified by immobilized metal affinity chromatography using a HisTrap HP column (GE Healthcare, Brøndby, Denmark) as described previously [13]. Finally, the buffer was exchanged to $10 \mathrm{mM}$ citrate phosphate buffer ( $\mathrm{pH}$ 8.0) using PD-10 desalting columns (GE Healthcare, Brøndby, Denmark) according to the manufacturer's protocol. Protein concentration was estimated using the BCA assay (Thermo
Fisher Scientific, Roskilde, Denmark) with bovine serum albumin as standard.

\subsection{Chemo-enzymatic cascade reactions}

Method I: A total of $550 \mathrm{mg}$ of GlcNAc $(250 \mathrm{mM})$ and $3.12 \mathrm{~mL}$ of $\mathrm{Et}_{3} \mathrm{~N}(2.25 \mathrm{M})$ was dissolved in $6.88 \mathrm{~mL} \mathrm{dH}_{2} \mathrm{O}$ in a $50 \mathrm{~mL}$ round-bottomed flask. The resulting solution was cooled to $0^{\circ} \mathrm{C}-4^{\circ} \mathrm{C}$ and agitated with a magnetic stirrer. The reaction was started by the addition of $1.27 \mathrm{~g}$ DMC $(750 \mathrm{mM})$ and stirring continued for $15 \mathrm{~min}$. Afterward, the solution was neutralized using $\mathrm{HCl}(2 \mathrm{M})$ and the $\mathrm{pH}$ was checked to be approximately 8.0 using a pH electrode (SlimTrode, Hamilton, Switzerland). Then, $100 \mu \mathrm{L}$ of the neutralized reaction was added to $42.8 \mathrm{mg}$ of $\beta$-lactose in a $2 \mathrm{~mL}$ tube. The reaction was started by addition of $100 \mu \mathrm{L}$ phosphate citrate buffer (10 mM, pH 8.0) and $50 \mu \mathrm{L}$ purified enzyme $(0.27 \mathrm{mg} / \mathrm{mL})$, so that final concentrations of $100 \mathrm{mM}$ GlcNAc oxazoline and $500 \mathrm{mM} \beta$-lactose were reached. The tube was incubated in a thermomixer (Eppendorf AG, Hamburg, Germany) at $25^{\circ} \mathrm{C}$ and $950 \mathrm{rpm}$ over $24 \mathrm{~h}$.

Method II: A total of $33.2 \mathrm{mg}$ of GlcNAc $(150 \mathrm{mM})$ and $184 \mathrm{mg}$ of $\mathrm{Na}_{3} \mathrm{PO}_{4}(1.125 \mathrm{M})$ was dissolved in $0.9 \mathrm{~mL}$ $\mathrm{dH}_{2} \mathrm{O}$ in a $2 \mathrm{~mL}$ tube. The resulting solution was cooled to $0{ }^{\circ} \mathrm{C}-4{ }^{\circ} \mathrm{C}$ and agitated with a magnetic stirrer. To start the reaction, $97.7 \mathrm{mg}$ of CDMBI ( $450 \mathrm{mM}$ ) was added and stirring continued for $2 \mathrm{~h}$ at $4^{\circ} \mathrm{C}$. Afterward, the solution was neutralized using $\mathrm{HCl}(2 \mathrm{M})$ and the $\mathrm{pH}$ was checked as in method I. The precipitated 1,3-dimethyl-1H-benzimidazol-3-ium chloride (DMBI) was removed using a centrifugal filter (3K MWCO, VWR, Søborg, Denmark). Then, 166.7 $\mu \mathrm{L}$ of the neutralized reaction was added to $42.8 \mathrm{mg}$ 
of $\beta$-lactose in a $2 \mathrm{~mL}$ tube. The reaction was started by the addition of $33.3 \mu \mathrm{L}$ phosphate citrate buffer $(10 \mathrm{mM}$, $\mathrm{pH} 8.0)$ and $50 \mu \mathrm{L}$ of purified enzyme $(0.27 \mathrm{mg} / \mathrm{mL})$, so that similar final concentrations as described previously were reached. The tube was incubated as described previously.

\subsection{Enzymatic transglycosylation using purified GIcNAc oxazoline (benchmark method)}

For investigation of the general ability to utilize GlcNAc oxazoline as a substrate by $\mathrm{HEX}_{\text {GTEPG }}$, commercially supplied GlcNAc oxazoline was used in transglycosylation reactions. These were carried out by the addition of $100 \mu \mathrm{L}$ GlcNAc oxazoline solution (250 mM in citrate phosphate buffer (10 mM, pH 8.0)) to $42.8 \mathrm{mg}$ of $\beta$-lactose in a $2 \mathrm{~mL}$ tube. To start the reaction, $100 \mu \mathrm{L}$ of citrate phosphate buffer (10 mM, pH 8.0) and $50 \mu \mathrm{L}$ of purified enzyme $(0.27 \mathrm{mg} / \mathrm{mL})$ was added, so that similar final concentrations as described previously were reached. The tube was incubated as described previously.

All reactions (methods I and II and benchmark method) were done in triplicate. Blanks were prepared as described previously, but instead of purified enzyme, buffer was added. Each reaction was terminated by diluting the samples in $95{ }^{\circ} \mathrm{C}$ hot Milli-Q water (1:100). The diluted samples were filtered through a $10 \mathrm{kDa}$ AcroPrep advance 96-well filter plate (Pall, New York, NY, USA). The transglycosylation products were quantified by using high-performance anion exchange chromatography with pulsed amperometric detection as described later by using an LNT2 standard curve in the presence of $\beta$-lactose ( $5 \mathrm{mM})$. All LNT2 isomers were quantified on the basis of the external LNT2 standard described previously [13].

\subsection{High-performance anion exchange chromatography with pulsed amperometric detection}

The transglycosylation products were quantified by using an ICS3000 system (Dionex Corp., Sunnyvale, CA, USA) consisting of DP gradient pumps, an ICS5000 electrochemical detector, and a DC chromatography compartment coupled to an AS autosampler (Dionex Corp., Sunnyvale, CA, USA). A total of $10 \mu \mathrm{L}$ of the sample was injected. The compounds were separated on a CarboPac PA1 $(4 \times 250 \mathrm{~mm})$ analytical column equipped with a
CarboPac PA1 $(4 \times 50 \mathrm{~mm})$ guard column (Dionex Corp., Sunnyvale, CA, USA). Elution was performed under isocratic conditions with $\mathrm{NaOH}(75 \mathrm{mM})$ in deionized water for $20 \mathrm{~min}$ at a flow rate of $1 \mathrm{~mL} / \mathrm{min}$. Cleaning of the column was done after each injection with $\mathrm{NaOAc}$ (425 mM)/ $\mathrm{NaOH}$ (75 mM) supplemented with $0.017 \% \mathrm{NaN}_{3}$ for $5 \mathrm{~min}$ followed by re-equilibration with $\mathrm{NaOH}(75 \mathrm{mM})$ for $5 \mathrm{~min}$. Column and detector temperatures were $30^{\circ} \mathrm{C}$. The following waveforms, that is, pulse potentials and durations, were used for electrochemical detection: $0.1 \mathrm{~V}$ for $400 \mathrm{~ms}$ (integration for the last $200 \mathrm{~ms}$ ), ramp to $-2.0 \mathrm{~V}$ over $10 \mathrm{~ms},-2.0 \mathrm{~V}$ for $10 \mathrm{~ms}$, ramp to $0.6 \mathrm{~V}$ over $10 \mathrm{~ms}$, ramp to $-0.1 \mathrm{~V}$ over $10 \mathrm{~ms}$, and $0.1 \mathrm{~V}$ for $60 \mathrm{~ms}$. The data collection rate was $2.0 \mathrm{~Hz}$. Data was collected and analyzed on a computer equipped with Chromeleon 7.2 software (Dionex Corp., Sunnyvale, CA, USA). LNT2 was quantified from an external standard curve, which was manually computed.

\section{Results and discussion}

Due to the high $\mathrm{pH}$ values ( $>\mathrm{pH} 11)$ during the chemical reaction, it was necessary to first neutralize the reaction and then add the enzyme for the enzymatic transglycosylation reaction. For method I (utilizing $\mathrm{Et}_{3} \mathrm{~N}$ as $\mathrm{HCl}$ scavenger and DMC as reactant), no further work-up was necessary; the neutralized reaction solution was simply diluted to the desired theoretical concentrations and $\beta$-lactose was added as acceptor (in a fivefold excess) together with the enzyme. In method II (utilizing $\mathrm{Na}_{3} \mathrm{PO}_{4}$ as $\mathrm{HCl}$ scavenger and CDMBI as reactant), it was necessary to filter the reaction solution before neutralization, subsequent dilution, and addition of $\beta$-lactose and enzyme because the reacted CDMBI formed the insoluble DMBI. However, this phenomenon was already described in the original publication describing CDMBI as a reactant [15].

As depicted in Figure 1A and B, both cascade methods were suitable for transglycosylation reactions with maximum overall product concentrations after $18.5 \mathrm{~h}$ of $11.3 \pm 1.5 \mathrm{mM}$ for method I and $13.7 \pm 1.5 \mathrm{mM}$ for method II. As previously reported [8, 13], the reactions produced a product mixture of LNT2 and three other regioisomers of unknown structure with the same molecular weight. We presume the regioisomers are formed due to different binding modes of the acceptor in the active site. In contrast to the in situ generation of the oxazoline, the use of purified GlcNAc oxazoline from a commercial source (benchmark method) resulted in a significantly higher maximum overall product concentration after $6.5 \mathrm{~h}$ of 

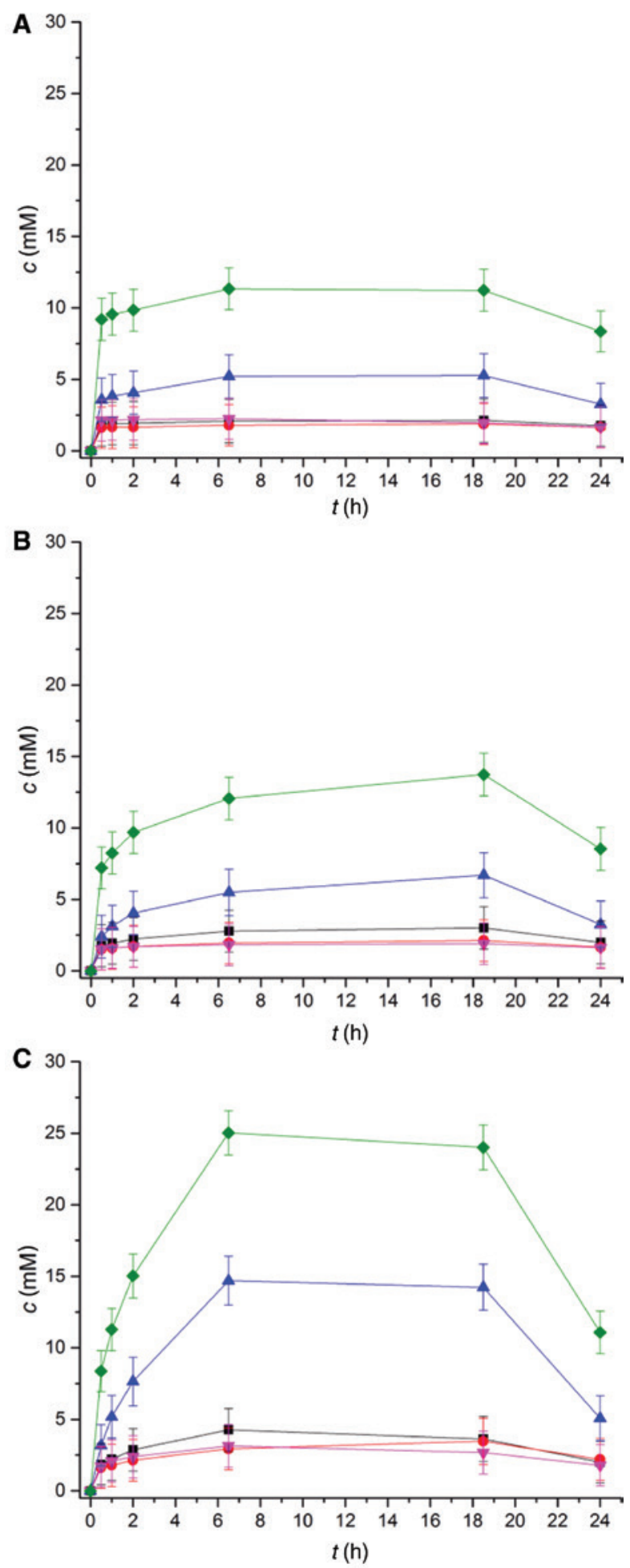

Figure 1: Progress of the different chemo-enzymatic cascade reactions during $24 \mathrm{~h}$. (A) Method I utilizing DMC; (B) method II utilizing $\mathrm{CDMBI}$; and $(\mathrm{C})$ benchmark method utilizing commercially available GICNAc oxazoline. Each data point represents the average of a triplicate sample. Black squares: LNT2; red circles: LNT2regioisomer 1; blue upward triangles: LNT2-regioisomer 2; magenta downward triangles: LNT2-regioisomer 3; green diamonds: total concentration of transglycosylation products.
$25.0 \pm 1.5 \mathrm{mM}$ (Figure 1C). Considering the high initial rate of product formation in the benchmark method (Figure 1C) compared with Figure $1 \mathrm{~A}$ and $\mathrm{B}$ (methods I and II), the point of maximum yield is probably in between the data points of 6.5 and $18.5 \mathrm{~h}$ approaching the maximum yield of $30 \%$, as reported in our previous study [13]. Differences in higher reaction rates and the observed secondary hydrolysis of the products could probably be explained by the higher enzyme dosage as compared with our previous work. The fact that the cascade approaches both gave lower product concentrations over the same studied reaction period cannot be explained rationally without further investigations. This might be due to either inhibitory effects by one of the reactants present or due to the fact that the GlcNAc oxazoline formation was not completed in the given amount of time. However, it is remarkable that the enzymatic transglycosylation reaction could be carried out at all in the presence of significant amounts of reagents such as $\mathrm{Et}_{3} \mathrm{~N}$, which was previously suspected to deactivate enzymes [15]. Furthermore, to the best of our knowledge, this study is the first successful report of an enzyme from the GH20 family utilizing the GlcNAc oxazoline as a donor molecule for the synthesis of an HMOlike molecule. In general, the use of a reactive oxazoline is more common for glycan remodeling using endo-acting $\beta$ - $N$-acetylglucosaminidases $[10,17]$ and it seems to be restricted to neutral to basic reaction conditions because fungal GH20 enzymes were described as being inactive on GlcNAc oxazoline due to their low pH optimum [18]. This hypothesis is further supported by another successful report on utilization of the reactive GlcNAc oxazoline for transglycosylation [19].

\section{Conclusion}

Despite the fact that the cascaded synthesis of HMO-like molecules was not as efficient as the one using the purified oxazoline, we could unequivocally demonstrate that $\beta-N$ acetylhexosaminidases from the GH20 family can be used for cascade reactions even in the presence of high concentrations of $\mathrm{Et}_{3} \mathrm{~N}$. Furthermore, the described reaction also enables the use of $N$-acetylglucosamine as a cheaper and more readily available donor for transglycosylation compared with the previously used $N, N^{\prime}$-diacetylchitobiose [8, 13]. The lower yields of the cascade reactions compared with the noncascade reaction indicate that further optimization of the reaction conditions is required to increase the yields and also to determine the limiting factors of the current setup, which is all part of ongoing research. The 
further development of a one-pot reaction could involve the compartmentalization of the reaction using a $\mathrm{pH}$ sensitive nanofiltration membrane as described for other reactions [20].

Acknowledgments: We are grateful to Birgitte Zeuner for help with the high-performance anion exchange chromatography with pulsed amperometric detection analysis.

\section{References}

1. Bode L. Human milk oligosaccharides: every baby needs a sugar mama. Glycobiology 2012;22:1147-62.

2. Bode L. The functional biology of human milk oligosaccharides. Early Hum Dev 2015;91:619-22.

3. Zeuner B, Vuillemin M, Holck J, Muschiol J, Meyer AS. Loop engineering of an $\alpha-1,3 / 4$-L-fucosidase for improved synthesis of human milk oligosaccharides. Enzyme Microb Technol 2018;115:37-44.

4. Zeuner B, Muschiol J, Holck J, Lezyk M, Gedde MR, Jers C, et al. Substrate specificity and transfucosylation activity of GH29 $\alpha$-L-fucosidases for enzymatic production of human milk oligosaccharides. New Biotechnol 2018;41:34-45.

5. Lezyk M, Jers C, Kjaerulff L, Gotfredsen CH, Mikkelsen MD, Mikkelsen JD. Novel $\alpha$-L-fucosidases from a soil metagenome for production of fucosylated human milk oligosaccharides. PLoS One 2016;11:e0147438.

6. Nyffenegger C, Nordvang RT, Jers C, Meyer AS, Mikkelsen JD. Design of Trypanosoma rangeli sialidase mutants with improved trans-sialidase activity. PLoS One 2017;12:e0171585.

7. Nordvang RT, Nyffenegger C, Holck J, Jers C, Zeuner B, Sundekilde UK, et al. It all starts with a sandwich: identification of sialidases with trans-glycosylation activity. PLoS One 2016;11:e0158434.

8. Nyffenegger C, Nordvang RT, Zeuner B, tężyk M, Difilippo E, Logtenberg MJ, et al. Backbone structures in human milk oligosaccharides: trans-glycosylation by metagenomic $\beta$ - $N$-acetylhexosaminidases. Appl Microbiol Biotechnol 2015;99:7997-8009.
9. Lombard V, Golaconda Ramulu H, Drula E, Coutinho PM, Henrissat B. The carbohydrate-active enzymes database (CAZy) in 2013. Nucleic Acids Res 2014;42:D490-5.

10. Slámová K, Bojarová P. Engineered $N$-acetylhexosamine-active enzymes in glycoscience. Biochim Biophys Acta - Gen Subj 2017;1861:2070-87.

11. Liu T, Duan Y, Yang Q. Revisiting glycoside hydrolase family $20 \beta$ - $N$-acetyl-D-hexosaminidases: crystal structures, physiological substrates and specific inhibitors. Biotechnol Adv 2018;36:1127-38.

12. Zeuner B, Nyffenegger C, Mikkelsen JD, Meyer AS. Thermostable $\beta$-galactosidases for the synthesis of human milk oligosaccharides. New Biotechnol 2016;33:355-60.

13. Jamek SB, Muschiol J, Holck J, Zeuner B, Busk PK, Mikkelsen JD, et al. Loop protein engineering for improved transglycosylation activity of a $\beta-N$-acetylhexosaminidase. ChemBioChem 2018;19:1858-65.

14. Noguchi M, Tanaka T, Gyakushi H, Kobayashi A, Shoda SI. Efficient synthesis of sugar oxazolines from unprotected $\mathrm{N}$-acetyl-2amino sugars by using chloroformamidinium reagent in water. J Org Chem 2009;74:2210-2.

15. Noguchi M, Fujieda T, Huang WC, Ishihara M, Kobayashi A, Shoda SI. A practical one-step synthesis of 1,2-oxazoline derivatives from unprotected sugars and its application to chemoenzymatic $\beta$ - $N$-acetylglucosaminidation of disialo-oligosaccharide. Helv Chim Acta 2012;95:1928-36.

16. Studier FW. Protein production by auto-induction in high density shaking cultures. Protein Expr Purif 2005;41:207-34.

17. Slámová K, Bojarová P, Petrásková L, Křen V. $\beta-N$ acetylhexosaminidase: what's in a name...? Biotechnol Adv 2010;28:682-93.

18. Slámová K, Krejzová J, Marhol P, Kalachova L, Kulik N, Pelantová $\mathrm{H}$, et al. Synthesis of derivatized chitooligomers using transglycosidases engineered from the fungal GH20 $\beta-N$ acetylhexosaminidase. Adv Synth Catal 2015;357:1941-50.

19. André-Miral C, Koné FM, Solleux C, Grandjean C, Dion M, Tran V, et al. De novo design of a trans- $\beta$ - $N$-acetylglucosaminidase activity from a GH1 $\beta$-glycosidase by mechanism engineering. Glycobiology 2015;25:394-402.

20. Nordvang RT, Luo J, Zeuner B, Prior R, Andersen MF, Mikkelsen JD, et al. Separation of $3^{\prime}$-sialyllactose and lactose by nanofiltration: a trade-off between charge repulsion and pore swelling induced by high pH. Sep Purif Technol 2014;138:77-83. 